\title{
Climate change induced marginality: Households' vulnerability in the meal consumption frequencies
}

\author{
Hasan, Mohammad Monirul \\ Department of Economic and Technological Change, Center for Development Research (ZEF), University of Bonn, Germany
}

Email address:

monir1021@gmail.com

To cite this article:

Hasan, Mohammad Monirul. Climate Change Induced Marginality: Households' Vulnerability in the Meal Consumption Frequencies. American Journal of Environmental Protection. Vol. 3, No. 3, 2014, pp. 103-112. doi: 10.11648/j.ajep.20140303.11

\begin{abstract}
The paper examines the impact of recent cyclones Sidr and Aila on the vulnerability of the meal consumption frequencies of the marginalized poor households in the southern part of Bangladesh where tropical cyclones persuaded by adverse effect of climate change hit repeatedly the coastal districts. Last two cyclones Sidr in 2007 and Aila in 2009 invaded the southern part of Bangladesh and caused huge death tolls and casualties. The nexus among climate change-marginality and vulnerability is the main focus here. Households become marginalized when cyclones destroy houses, infrastructure, drinking water, sanitation and cropping lands through upsurge of sea water ensuing breaking down the traditional agricultural production system. Propensity score matching technique is used to find the impact of cyclones on vulnerability as the problem of selection biasedness may arise. From the various matching techniques it is evident that households those are affected by any of the last two cyclones Sidr and Aila exhibit about 9 to 14 percentage increase of the vulnerability in the meal consumption frequencies of the marginalized rural households. The ordered probit model demonstrate that the marginal effect of some household characteristics such as number of income sources, non-agricultural activities, migration, education, agricultural land, savings and safe drinking water exhibit significant negative effect whereas wage-earning and distance from roads exhibit positive effect with both extreme and moderate vulnerability.
\end{abstract}

Keywords: Climate Change, Marginality, Vulnerability, Meal Consumption, Propensity Score Matching, Probit Model

\section{Introduction}

Southern part of Bangladesh such as Barisal and Khulna division are vulnerable to tropical cyclones, adverse effect of climate change and salinity due to upsurge of sea water in the agricultural land [1]. Households in this region are vulnerable in food and non-food consumption due to salinity in the agricultural land. Land is the terrestrial bio-productive system that includes soil, vegetation, biota and ecological-hydrological processes that operate within the system [2]. Salinity in the agricultural land is a kind of land degradation which destroys the agricultural productivity as well as the potable water security. Hence land degradation could be addressed as the reduction of the land capacity to provide ecosystem services over a long period of time [3]. It decreases the availability of the basic necessities which are vital for human wellbeing such as fuel, water, infrastructure materials, indigenous foods and medicinal plants; increase the time and effort to obtain such items [4]. Conversely the term marginality is a multi-disciplinary concept of poverty which can be defines as "an involuntary position and condition of an individual or group at the margins of social, political, economic, ecological, and biophysical systems, that prevent them from access to resources, assets, services, restraining freedom of choice, preventing the development of capabilities, and eventually causing extreme poverty" [5]. The nexus among marginality-climate change and vulnerability is obvious and will be analyzed in this research framework with the context of southern part of Bangladesh focusing on three districts such as Khulna, Patuakhali and Satkhira. The paper focused on the vulnerability of the marginalized poor households because these households' monthly average income is less than USD 38 (BDT 3000) during lean period with geophysical disadvantages which is below the minimum $\$ 2$ set by World Bank.

Tropical climate and geophysical location drive Bangladesh more vulnerable to cyclones [6][7][8]. Poverty situation is much higher in Barisal (39.4\%) and Khulna (32.1\%) region than the country's average of $31.5 \%$ (HIES, 2010). Since 1995, more than 5 severe cyclones hit the 
country's southern part and on average almost every three years a severe cyclone is expected to hit Bangladesh coast [9]. Another study from [8] and [10] described that $10 \%$ of the tropical cyclone hits through the Bay of Bengal and one devastating cyclone invade the country every year. Having two-third land area under 5 meters above sea level, the extremely flat-low level topography of Bangladesh is vulnerable to storm surges in the lower-lying costal districts. The last two devastating cyclone Sidr in 2007 with an average wind speed of $223 \mathrm{~km}$ per hour caused 4,234 casualties and 55,282 injuries and cyclone Aila in 2009 caused 190 deaths, 7,103 injuries and affected 3.9 million people [11]. Half of the total cyclone related death in the whole world is from Bangladesh [12][13]. A frequent cyclone in the tropical region is the adverse effect of climate change [14]. Despite the lack of common consensus on the linkage between the climate change and tropical storms, it is widely believed that frequent storms and cyclones in the basins like Bay of Bengal is the adverse effect of climate change. The frequency of high-intensity storms in the selected ocean basins is predicted to be increased due to climate change and also varies depending on climate models [15]. Cyclone-induced damage is severe for human and biophysical life. Several studies evaluated the impact of various disasters on human lives.

Studies such as [16][17][18][19][20][21] emphasized in their research on river based disaster in Bangladesh. Numerical modeling and forecasting based research are found in [22][23][24][25][26]. Storm surges impact and mitigation are the main focus in the studies such as [27][28][29]. A substantial gap is evident in terms of quantitative research to see the impact of cyclones such as Sidr and Aila- the two major cyclone of Bangladesh on the meal consumption vulnerability of the marginalized poor households. The novelty of the paper is to fill the gap in this regard by exploring the dynamics of meal frequencies for those households who are affected by the cyclones comparing with not affected households.

Vulnerability to consumption is analogous to 'transient poverty', and argued as variability in the availability of physical capital, and adverse geographic conditions which influence transient poverty and hence vulnerability. [30][31] termed vulnerability as "defenselessness, insecurity and exposure to risk, shocks and stress". Authors in [32] outlined vulnerability as a "loss in forward looking welfare due to low expected consumption, high variability of consumption or both". Some literature addressed vulnerability as probability. The main difference between poverty and vulnerability is risk [33]. The poor households' credit constraint becomes more obstinate when they can't accumulate sufficient saving for the future because their average propensity to save is lower than the rich [34]. Disaster causes adverse effect on human life and health status. Adverse health shock creates a demand for credit to mitigate the shock if the household have insufficient saving to pay the healthcare bills [35]. Authors in [36] used fixed effects regressions model to examine the effects of idiosyncratic shocks on wellbeing. Rural vulnerability is mostly caused by both covariate and idiosyncratic shocks whereas urban one is caused by mostly idiosyncratic shocks [37].

Households are adversely affected by disaster and adopted some coping strategies. Among them the distress sale of assets, advance sale of labor and crop are pretty common. Additionally, migration and access to social safety net programs are also very apparent. Nevertheless these strides do not put them out of poverty. In consequence, marginalized poor households have to ration meals or have to starve for an extended period, which drives them to serious malnutrition and even death in extreme environments. The average monthly wage-income of the sample households continues to fall from April to September and again start to rise to the benchmark income level of Tk. 3,000 from September to November. The average income only crosses the benchmark income from November to February. These households can enjoy average good income in wage earning for only 3-4 months in a year [38].

There is seasonality in the meal consumption frequencies of the marginalized poor households of this region. They reported that during normal time when they have adequate employment can enjoy 3 full meals but when there is lack of jobs due to seasonality in agriculture (lean period) can only avail single meal or meal rationing for 2 times daily. Some households have to starve even during lean period because they don't have adequate savings to mitigate this seasonal shock. Hence vulnerability is described here as the difference between the two periods which is expressed in the transition matrix Table 1.

Table 1. Dynamics of meal frequencies of the marginalized poor households

\begin{tabular}{ccccc}
\hline \multirow{2}{*}{ Transition matrix of vulnerability } & \multicolumn{3}{c}{ Meal frequencies in Lean period } \\
\cline { 3 - 5 } & & Occasional Starvation & Consumption rationing & Full 3 meals in a day \\
\hline \multirow{2}{*}{$\begin{array}{c}\text { Meal frequencies in Normal } \\
\text { period }\end{array}$} & Occasional Starvation & $2^{\circ}$ & $-1^{\circ}$ & $-2^{\circ}$ \\
& Consumption rationing & $2^{\circ}$ & $1^{\circ}$ & $-1^{\circ}$ \\
\hline
\end{tabular}

Source: Author's calculation; Note: $2^{\circ}$ means two degree of vulnerability. Benchmark is 3 meals in a day.

Several authors such as Khandker et al. in [39], Hasan, M Monirul in [40] and InM in [41] adopted this approach of meal frequencies to find out the impact of other variables.
The vulnerability matrix in Table 1 , measures the extent of vulnerability. The bench mark level is three times meal in a day for every household with full satisfaction. A household is 
in vulnerability of degree 1 when a household consumes 3 meals in normal time and only 2 meals in lean time. Hence variations from 3 times to 1 time, 2 times to 1 time or continuing 1 time in both periods are defined as $2^{\circ}$ vulnerability. Likewise 3 times to 2 times or 2 times in both periods are defined as $1^{\circ}$ vulnerability. Alternatively, some households reported that they are better off during the lean period of their occupational income. Consequently, they exhibited an improved number of meal consumption frequencies during their self-nominated lean period. So $-1^{\circ}$ and $-2^{\circ}$ are the degree of better off where $-2^{\circ}$ is superior to $-1^{\circ}$. Nevertheless some households having $0^{\circ}$ of vulnerability implying their meal frequencies do not change in any period.

\section{Data and Methods}

\subsection{Sample}

The study is benefited from the data provided jointly by the Institute of Microfinance (InM) and Palli Karma Sahayak Foundation (PKSF), Bangladesh. PKSF made a census survey in three districts- Khulna, Patuakhali and Satkhira (Figure 1). Among the census covered 60,053 households, baseline sample of 4000 households have been taken randomly and conducted the survey in 2011 and it retains finally 3,977 households. The criteria for selecting marginalized poor households were as follows- (1) Monthly income less than or equal to 3,000 Taka (equivalent to EUR 30) per household during lean period; or (2) Primary occupation of the household head is daily wage earning (in farming, fishing, logging, honey collection or other activities); or (3) Having less than or equal to 50 decimal cultivable land.
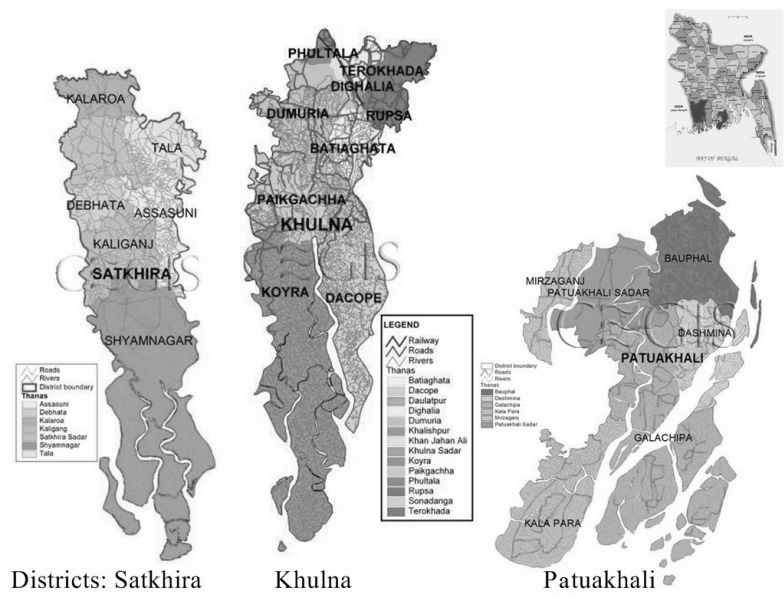

Source: Maps are generated by CEGIS. Maps are assembled by Author. Map of Bangladesh (upper captioned) is from PKSF.

Figure 1. Study area in Southern Bangladesh: Three districts

\subsection{Method}

Propensity Score Matching (PSM) - a microeconometric technique is sophisticated and increasingly used tool for program evaluation where there is a possibility of selection bias and confounding issues. PSM resolves this problem. It works as for each individual in the treatment group a matching individual is found on the basis of observable characteristics with an identical individual in the non-treatment group. Then mean effect of treatment is calculated as the average difference of outcomes of the two groups [42]. If no match is found, households are dropped. Several authors used this approach for program evaluation such as [43][39][44][45]. The paper uses PSM to see the impact of last two cyclones Sidr in 2007 and Aila in 2009 on meal consumption vulnerability of the marginalized poor households of southern Bangladesh. In order to apply PSM, individual who was affected by any of the two cyclones (Sidr and Aila) is ascribed as treatment group and otherwise as non-treatment group which can be defined as-

$y_{i}=c_{-}$aff fect $=\left\{\begin{array}{l}1 \text { if household was affected by cyclones } \\ 0 \quad \text { if household wast't af fected by cyclones }\end{array}\right.$

The outcome of cyclone affect households are defined as $y_{1}$ and the not-affect $\left(c_{-}\right.$affect $\left.=0\right)$ as $y_{0}$. The aim is to ascertain the average treatment effect on the treated (ATT). The average treatment effect on the treated is defined as -

$\mathrm{ATT}=\mathrm{E}\left(\mathrm{y}_{1}-\mathrm{y}_{\mathrm{O}} / \mathrm{c} \_\right.$affect $\left.=1\right)=\mathrm{E}\left(\mathrm{y}_{1} / \mathrm{c} \_\right.$affect $\left.=1\right)-\mathrm{E}\left(\mathrm{y}_{0} / \mathrm{c} \_\right.$affect $\left.=0\right)$

The first portion of the equation (1) is observable whereas the second portion is not observable because it is not possible to observe the same individuals as affected as well as not-affected simultaneously. Propensity score matching can remove this problem to estimate $E\left(y_{0} / c_{-}\right.$affect $\left.=0\right)$.

Observational studies estimating ATT arise problems in the non-randomness of the selection of the affected and not-affected group and consequently the estimation of ATT suffers from biasedness. PSM summarizes the pre-affected characteristics of subject into a single index variable (the propensity score) which is then used to generate the matching. Estimating the propensity score, any standard model such as Logit or Probit is used. For the purpose of estimation probit model is used as follows-

$$
\begin{aligned}
P\left(y_{i}\right. & =1 \mid x)=P\left(y_{i}^{*}>0 \mid x\right) \\
& =p\left(x_{i}^{\prime} \beta+z_{i}>0 \mid x\right) \\
& =P\left(\varepsilon_{i}>-x_{i}^{\prime} \beta \mid x\right) \\
& =1-F\left(-x_{i}^{2} \beta\right]
\end{aligned}
$$

Assuming error terms are independently and normally distributed:

$$
\begin{aligned}
F\left(y_{1}=\left.1\right|_{x}\right) & =1-\phi\left(-\frac{x_{1}^{\prime} \beta}{\sigma}\right), \sigma \equiv 1 \\
& =\Phi\left(x_{i} \beta\right)
\end{aligned}
$$


PSM method works in three steps- (1) Estimating a model of $c \_$affect, (2) defining the region of common support and balancing tests, (3) Matching affected to not-affected. Matching of treatment and control uses various ways such as (1) Nearest-neighbor matching, (2) Caliper or radius matching, (3) Stratification or interval matching, (4) Kernel and local linear matching, (5) Difference-in-difference matching etc.

In PSM, the first phase is to calculate the propensity score and satisfy the balancing property. Score which is within the range of lowest and highest estimated values for households in the treatment group, is termed area of common support. With the propensity score produced, the outcome of interest between treatment group and matched control group is compared.

To see the marginal effect of some variables on meal consumption vulnerability, it is used the ordered probit model which can be shown as-

$$
V_{i}^{*}=X_{i}^{\prime} \beta+\delta D_{i}+\varepsilon_{i}
$$

Here $v_{i}$ represents the degrees of vulnerability, $x_{i}$ represents continuous variables and $D_{i}$ represents dummy variables.

\section{Results}

\subsection{Descriptive Analysis}

Descriptive analysis of the marginalized poor households incorporates households' characteristics, socio-economic characteristics, and community characteristics. The average age of household head is 42 years and their average years of schooling are 2 years. Among them, 14\% of the household heads are female and average household size is 4 (Table 2). In occupation, about $53 \%$ of the households are wage earners and about $10 \%$ of the households are self-employed in agriculture and $22 \%$ of the households are self-employed in non-agriculture which are mostly vendors, small traders, and rickshaw-van puller. Besides, about $13 \%$ of the household head migrates for jobs opportunities in other places. In infrastructure amenities, Almost $11 \%$ have access to electricity, $79 \%$ avail safe-water from tube-well or pipe-water and $63 \%$ possess sanitary latrine.

Table 2. Summery statistics for selected variables from benchmark household survey.

\begin{tabular}{lll}
\hline Characteristics & Mean & $\begin{array}{l}\text { Standard } \\
\text { Deviation }\end{array}$ \\
\hline Female & $14.2 \%$ & $34.9 \%$ \\
Age (Years) & 42.6 & 13.8 \\
Years of schooling & 2.0 & 3.1 \\
Wage worker & $53.33 \%$ & $49.90 \%$ \\
Self-employed in agriculture & $9.88 \%$ & $29.85 \%$ \\
Self-employed in non-agriculture & $22.08 \%$ & $41.48 \%$ \\
Live outside the household for work & $12.75 \%$ & $33.36 \%$ \\
Household size (Number) & 4.0 & 1.46 \\
Access to electricity & $11.34 \%$ & $31.71 \%$ \\
Access to tube-well or tap water & $79.16 \%$ & $40.62 \%$ \\
Access to sanitary latrine & $63.16 \%$ & $48.24 \%$ \\
\hline
\end{tabular}

\begin{tabular}{lll}
\hline Characteristics & Mean & $\begin{array}{l}\text { Standard } \\
\text { Deviation }\end{array}$ \\
\hline Distance from main road (kilometer) & 8.0 & 14.3 \\
Distance from small market place & 1.9 & 1.6 \\
(kilometer) & 13.0 & 35.9 \\
Total owned land (Decimal) & 4.9 & 27.6 \\
Total agricultural land (Decimal) & 0.4 & 1.0 \\
Number of cows & 0.6 & 1.5 \\
Number of goats & 4.0 & 5.5 \\
Number of poultry & 58,940 & 123,666 \\
Asset value including land (Taka) & $1,334.86$ & 7,129 \\
Savings (Taka) & $49,903.13$ & 38,268 \\
Total Income (Taka) & $39,409.01$ & 15,110 \\
Expenditure on food (Taka) & $13,271.18$ & 9,965 \\
Non-foods expenditure (Taka ) & $7,452.28$ & 17,634 \\
Loss in Cyclone Sidr (Taka) & $12,841.48$ & 29,815 \\
Loss in Cyclone Aila (Taka) & $1,699.58$ & 7,228 \\
Loss in crisis last yr. (2010-11) (Taka) & $5,404.71$ & 14,634 \\
Unmet loss in Sidr ('07) (Taka) & $9,259.75$ & 26,666 \\
Unmet loss in Aila ('09) (Taka) & $1,105.04$ & 5,417 \\
Unmet crisis in 2010-11 (Taka) & $3,351.57$ & 7,121 \\
Social Safety Net received (Taka) & $24.74 \%$ & $43.15 \%$ \\
Household in char areas & & \\
\hline
\end{tabular}

Source: Author's calculation.

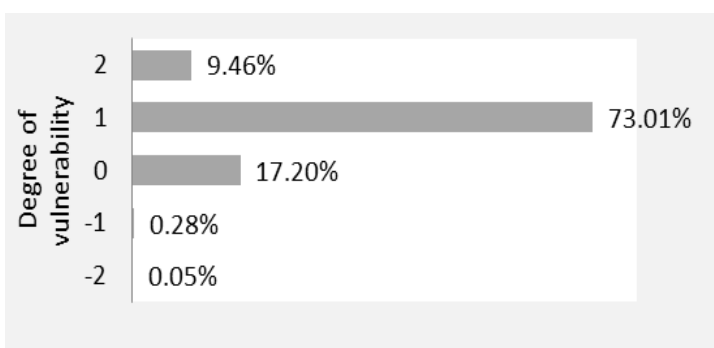

Source: Author's calculation. Note: Degree of vulnerability ranges from +2 to -2 , where +2 represent the highest level of vulnerability; 0 represents there is no vulnerability in food consumption between normal period and lean period.

Figure 2. Percentage of household encountering the different level of vulnerability $(N=3,912)$

Households' average distance from the main road is 8 kilometres and from small market is 1.9 kilometers. Households' average landholding is 13 decimals and among them 4.9 decimals are for agriculture. Average asset value of the households is about BDT 59,000 and the total saving is about BDT 1,334. Household earns average yearly income of BDT 49,903 among which BDT 39,409 is for food expenditure and BDT 13,271 is for non-food expenditure. Households' average of total unmet loss (loss that is not recovered) in Sidr is BDT 5,404 and in Aila is BDT 9,260. $25 \%$ of the households live in the geographically hard-to-reach area which is called river basin or Char area (Table 2). About $73 \%$ of the total households fall in the vulnerable group 1 (Figure 2) and only $17 \%$ is not affected by this kind of vulnerability. The worst case is the 2 degree of vulnerability which includes $9.46 \%$ households.

\subsection{Crisis and Coping Strategy}

According to Table 3, 23\% of the sample marginalized poor households were affected only by cyclone Sidr in 2007, $38 \%$ by only cyclone Aila in 2009 and about $75 \%$ were 
affected by any one of these two. 14\% of them reported that they were affected by the both cyclones and about $25 \%$ reported that they were not affected by any of these two cyclones.

Households experienced different types of losses in last two big cyclones Sidr and Aila. Majority of the households incurred house broken, death of livestock, damage of trees and garden, loss of other assets, fish-farming place destroyed, crop destroyed and death of family members. About 47\% households reported break down of houses in Aila and 55\% reported in Sidr (Figure 3). About 19\% of the households lost their livestock in each of the cyclone. Aila also destroyed the trees of $20 \%$ of households. Conversely it was only $12 \%$ in Sidr. Other damages are low in terms of percentage value.

Table 3. Percentage of households are affected by the last two major cyclones -Sidr in 2007 and Aila in 2009

\begin{tabular}{ll}
\hline Households affected by & $\mathbf{( N = 3 , 9 7 7 )}$ \\
\hline Only Sidr & $23 \%$ \\
Only Aila & $38 \%$ \\
At least one of these cyclones & $75 \%$ \\
Both cyclones & $14 \%$ \\
Not affected by any of these two & $25 \%$ \\
\hline
\end{tabular}

Source: Author's calculation

Households applied various remedial measures to cope with the crisis incurred. Among them the first one that comes in mind is savings $(22 \%$ households used this strategy). Besides savings other assistances program such as - from government and non-governmental organization, from relatives are worth to mention (Figure 4). 9\% of households received government assistance in both cyclones and about 6 to 8 percentage received non-government assistances. Furthermore 9\% marginalized households after Aila and $11 \%$ after Sidr seek assistance from relatives.

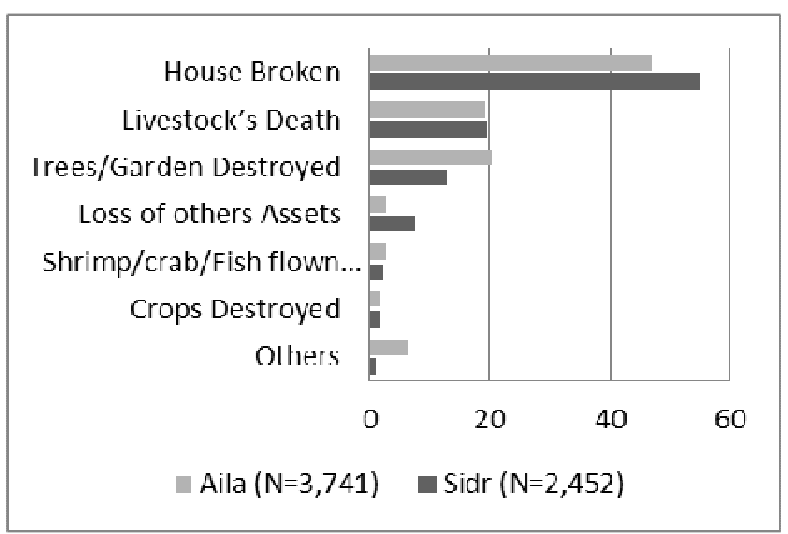

Source: Author's calculation. Values are shown in percentage.

Figure 3. Percentage of households incurred losses after two big cyclones Sidr in 2007 and Aila in 2009.

It is also noteworthy from Figure 4 that almost $45 \%$ households after Aila and 40\% after Sidr couldn't attempt any remedial measure which drives them to more vulnerable state and also to further degree of marginalization. Almost
$3 \%$ of the households also took loan from informal sources. On the other hand, advanced sale of labor, crops, animals and lands are pretty common among the vulnerable groups. Some households took loans from microcredit institutions as a coping strategy against the adverse effect of climate change. They first try to meet the immediate shock and afterwards try generating consistent income. But because of lack of infrastructure and market access it is very hardly that they could successfully recovered their incurred permanent loss.

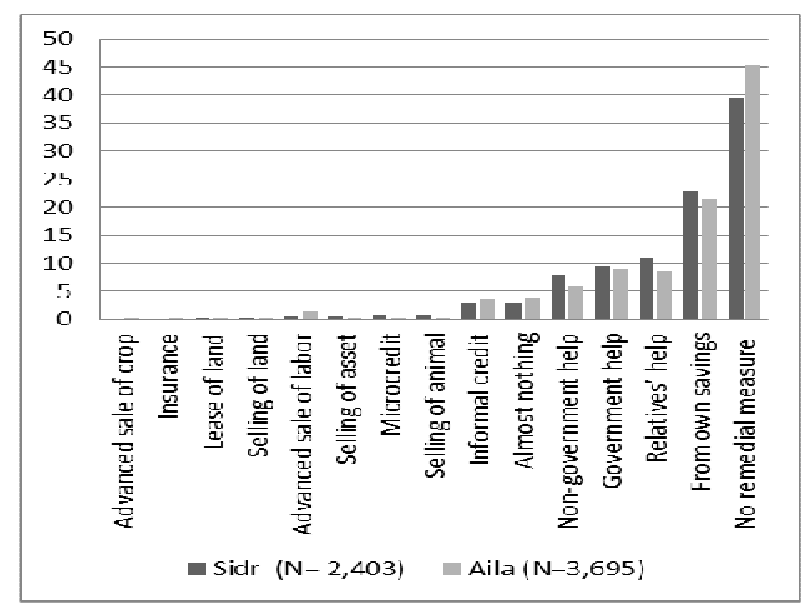

Source: Author's calculation;

Figure 4. Percentage of households got remedial measure from various sources after two big cyclones Sidr in 2007 and Aila in 2009.

\subsection{Land and Vulnerability}

Land is an important asset to determine vulnerability. The marginalized rural households are heavily dependent on land and agricultural sector. Any attract from natural disaster first strict on land and agricultural sector. Rural households become more marginalized and vulnerable if they can't recover the losses from disaster. The present study analyzes the types of land and degrees of vulnerability. It is evident from the Table 4 that the more vulnerable households the less access to land and especially the agricultural land they possess. Hence makes the households more vulnerable to risk and climate change. The adverse effect of climate change could be found if the productivity of land and composition of land is analyzed. The households those don't suffer from any kind of vulnerability in meal frequencies in any period have more access to land than those who suffers. Zero degree vulnerable groups has more land compared to the other two groups.

In total land assets, zero degree vulnerable groups possess almost 24 decimals of land whereas degree 1 and 2 group have 11 decimals and 8 decimals respectively. The distribution of land is a structural problem which is clearly pictured in this table. The less land household has, the more vulnerable is the household in meal consumption frequencies. 2 degree vulnerable group has only 6.7 decimals of land compare to the 21 decimal land of zero degree vulnerable group and 10.33 decimals of one degree 
vulnerable group. The same trend is also true for the agricultural land, where most vulnerable group has only 1.57 decimals of agricultural land. Zero degree vulnerable group has average land of 11 decimals which is higher than the extreme vulnerable group. In terms of free/public land access or acquisition of Khas land, the most vulnerable group is also marginalized from the societal point of view because this group has only 1 decimal of land compared to the 7 decimals of land of non-vulnerable group. So land is an important factor to determine vulnerability especially for the rural agricultural households.

Table 4. Types of land in decimal and vulnerability

\begin{tabular}{lllll}
\hline $\begin{array}{l}\text { Degree of } \\
\text { vulnerability }\end{array}$ & $\mathbf{0}$ & $\mathbf{1}$ & $\mathbf{2}$ & Overall \\
\hline $\begin{array}{l}\text { Types of owned } \\
\text { land }\end{array}$ & $\mathbf{( N = 6 7 3 )}$ & $\mathbf{( N = 2 8 5 6 )}$ & $\mathbf{( N = 3 7 0 )}$ & $\mathbf{( N = 3 9 7 7 )}$ \\
\hline Total land & 23.70 & 11.26 & 7.72 & 12.99 \\
Using land & 20.78 & 10.33 & 6.70 & 11.73 \\
Non using land & 1.10 & 0.37 & 0.44 & 0.49 \\
$\begin{array}{l}\text { Agri. land } \\
\text { Free/public land } \\
\text { enjoyed }\end{array}$ & 10.89 & 3.95 & 1.57 & 4.87 \\
\hline
\end{tabular}

Source: Author's calculation;

\subsection{Econometric Regression Results}

Two models are used in this study- propensity score matching (PSM) and ordered probit model. PSM shows the impact of cyclones on meal consumption vulnerability and the extent of vulnerability generated by cyclones. Ordered probit regression model represents the marginal effect of some selected variables on this meal consumption vulnerability. From this result it could be said that responsiveness of vulnerability due to changes in one specific variable.

\subsection{Propensity Score Matching (PSM)}

Propensity Score Matching technique is a sophisticated tool to see the impact of a specific variable. It removes the selection bias of the treated group and compares the observable characteristics with the non-treated group and displays the results by several matching methods. The study uses cyclones as a treatment variable which means the treatment variable is a dummy variable of disaster affected households in any of last two cyclones. After estimating the propensity score, it is applied the matching methods to get the ATT estimation. Table 5 represents the all matching methods results which are statistically significant. In Nearest Neighbor matching method, it postulates that $14 \%$ increase in the degree of vulnerability for a household being affected by cyclones.

Table 5. Estimation of Average Treatment Effect for the Treated (ATT): Impact of cyclones on vulnerability

\begin{tabular}{llllll}
\hline Matching Methods & Number of treated & Number of control & ATT & Standard Error & t-value \\
\hline Nearest Neighbor method & 171 & 130 & $0.140^{* *}$ & 0.071 & 1.984 \\
Stratification method & 170 & 909 & $0.087^{*}$ & 0.047 & 1.848 \\
Kernel Matching method & 171 & 908 & $0.096^{* *}$ & 0.041 & 2.327 \\
\hline
\end{tabular}

Source: Author's calculation. Note: ${ }^{* * *} \mathrm{p}<0.01,{ }^{*} \mathrm{p}<0.05,{ }^{*} \mathrm{p}<0.1$

The t-value is statistically significant at 5\% level. In Stratification method, it says that if a households is affected by any of the two cyclones it increases the meal consumption vulnerability by $8.7 \%$ which is at $10 \%$ level of significance ( $\mathrm{t}$-value is 1.848). In the Kernel matching technique, this effect is about $9.6 \%$ which is significant at $5 \%$ level. So it is apparent that being affected by any of the cyclones, households incur almost 9 to 14 percent of meal consumption vulnerability. It is evident from Table 5 that the cyclones affected households are more vulnerable than the households that are not affected by cyclones. The technique matches each individual in the treatment group with individuals sharing similar characteristics in the control group.

\subsection{Marginal Effect on Vulnerability}

Vulnerability can be determined by so many factors such as socio-economic factors of vulnerability, political factor of vulnerability, geophysical and climate change factor of vulnerability. To find the extent of vulnerability some household and community level characteristics is used. It is evident from table 6 that the higher the source of income of a household has, the less vulnerable it is. It means that for an additional source of earning, extreme vulnerability is reduced by $1.6 \%$ point and moderate vulnerability is reduced by $0.9 \%$ point. Conversely, being a wage-earner increases the extreme vulnerability by $2.5 \%$ point and moderate vulnerability by $1.5 \%$ point which are at $1 \%$ level and $5 \%$ level of significance respectively. If household is engaged in non-agricultural works then both vulnerabilities are reduced significantly. Another way to reduce vulnerability in meal is to migrate to other places for employment. Results show that being migrated to other place could reduce extreme meal consumption vulnerability by $3.3 \%$ point and moderate vulnerability by $3.1 \%$ point both of which are at $1 \%$ level of significance. Result also shows female headed households are moderately vulnerable to meal consumption frequencies. Size of household doesn't show any causality with vulnerability. The effect of education is evident from the result. It shows for an additional year of schooling extreme vulnerability could be reduced by $0.5 \%$ point and moderate vulnerability by $0.3 \%$ point which is statistically significant. Household's permanent assets such as owned land and operational land and savings have negative causality with the degrees of vulnerability. The marginal effects of these 
variables are statistically significant but the extent of effect is very minimal. The infrastructure facility of the household is also very important determinant for vulnerability which implies for having access to safe drinking water, household could reduce extreme vulnerability by $2.9 \%$ point and moderate vulnerability by $1.2 \%$ point which are statistically significant at $1 \%$ level. Distance matters for vulnerability. For one kilometer distance of household from main road, both level of vulnerability increased by $0.1 \%$ point at $1 \%$ level of significance. Distance increases the transaction cost of economic activity for the households and business becomes unprofitable and unappealing.

Table 6. Marginal effects on vulnerability

\begin{tabular}{lll}
\hline Variables & $\begin{array}{l}\text { Extreme } \\
\text { vulnerability (2 } \\
\text { degree) }\end{array}$ & $\begin{array}{l}\text { Moderate } \\
\text { vulnerability (1 } \\
\text { degree) }\end{array}$ \\
\hline Number of income sources & $-0.016 * * *$ & $-0.009 * * *$ \\
HH is wage earner & $0.025 * * *$ & $0.015 * *$ \\
HH engaged in agriculture & -0.011 & -0.008 \\
HH engaged in non-agri. & $-0.023 * *$ & $-0.017 *$ \\
HH head migrated to other & $-0.033 * * *$ & $-0.031 * * *$ \\
place for employment & 0.017 & $0.008 * *$ \\
HH head is female & 0.002 & 0.001 \\
HH size & $-0.005 * * *$ & $-0.003 * * *$ \\
Education of HH head & $0.001 * * *$ & $0.001 * * *$ \\
Distance from main road & $-0.029 * * *$ & $-0.012 * * *$ \\
HH have safe water & $-0.000 * *$ & $-0.000 * *$ \\
HH total operational land & $-0.000 * * *$ & $-0.000 * * *$ \\
HH total own land & $-0.000 * * *$ & $-0.000 * *$ \\
HH savings &
\end{tabular}

Source: Author's calculation; Note: HH represents household. Note: *** $\mathrm{p}<0.01, * * \mathrm{p}<0.05, * \mathrm{p}<0.1$

\section{Discussion of Results}

The impact of last two big cyclones - Sidr in 2007 and Aila in 2009 have significant impact on meal consumption vulnerability. The novelty of this paper is that it deals with the marginalized poor households not all kinds of households of southern part of Bangladesh. Bangladesh is the hotspot for adverse effect of climate change where tropical climate and geophysical location could be ascertained as main factor [6][7][8][14]. According to [8] and [10], cyclones hit this country every year and causes huge death toll. The adverse effect of two major cyclones marginalized these households as result poverty becomes an inherited or structured problem among these households. This is because of permanent asset loss which is not recovered in the later stages. Land degradation as well as land loss are the major problems for the marginalized households which drives them into poverty which is also mentioned in [3][4]. The rationale for addressing these households as marginalized poor is that they possess less than 50 decimal of land and most of the households' income is less than BDT 3000 (EUR 30) during lean period. According to [5], they are the group at the margins of economic, ecological, and biophysical systems, that prevent them from access to resources, assets, services, restraining freedom of choice, preventing the development of capabilities, and eventually causing extreme poverty and hence the nexus between these three climate change-marginality-vulnerability is obvious. This paper finds results in line with the mentioned literature.

The paper identified how the climate change such as severe cyclones like Sidr and Aila make the households marginalized in terms of socio-economic point of views which at the end results vulnerability. Climate change induced marginality can be observed in the process of land degradation due to salinity in the cropping fields and income instability. Households having less agricultural land and those who are engaged in wage earning activities are more vulnerable than the households those are engaged in non-agriculture or self-employment activities. Marginal effect of non-agriculture activity is $2.3 \%$ which means that it can reduce extreme vulnerability by $2.3 \%$ and moderate vulnerability by $1.7 \%$. This process of marginalization prevents those households from the development of capabilities and freedom of choice which is the process of vulnerability [5]. So inadequate access to land is a very important factor for marginalization and climate change is very much associated with land degradation [6][7][8].

Like [30] the paper shows that vulnerability to meal consumption is a transient poverty which is caused by variability in the availability of physical capital, and adverse geographic conditions which influence transient poverty and hence vulnerability. Marginalized households have less income and savings which accumulates less physical capital. Along with this inadequate physical capital, they are obstructed in achieving of human capital which restricts them from developing the capability and freedom of choice [46]. The econometric results show that the marginal effect of number of income source on extreme vulnerability is $1.6 \%$ which means for an additional income source of the household extreme vulnerability will be reduced by $1.6 \%$ point and moderate vulnerability by $0.9 \%$ point. Again the adverse geographic condition which is measured here by distance and availability of drinking water also prove that these marginalized poor are vulnerable. The marginal effect of distance is $0.1 \%$ and safe-drinking water is $2.9 \%$ for the extreme vulnerability.

The studied result also in line with [31] result which termed vulnerability as the defenselessness, insecurity and exposure to risk and shocks. The sample households are vulnerable because they are adversely affected by frequent natural disasters which take away lives, assets, lands, crops and livestock lowering the physical endowment of the households and put them into income and food insecurity induced by partially the seasonality in agriculture which is also found in [37]. Lack of wage-earning scope during lean period and lack of physical capital and savings hinder them to invest in non-agricultural activity with the increasing transaction cost for marketing. Those who are engaged in non-agricultural activities are better off from this kind of adverse shocks.

Marginalized households are most vulnerable because as 
[33] addressed that the main difference between poverty and vulnerability is risk. Risk can be assessed by observing the marginal effect of different variables which is presented in table 6. Households are vulnerable because almost in every year at least one cyclone visits this region and the agricultural and wage-earning households are very much responsive to this shocks [8][10]. As results they are always in vulnerable state.

To identify the impact of this kind of shock such as cyclones on the household wellbeing is difficult because there arises a problem of selection bias. Which group is compared with which control households? They are really comparable? The problem of confounding and endogeneity questions the results of impact analysis which is called selection biasness. To address this problem of selection biasness propensity score matching (PSM) technique is used where the treated group is compared with the identical non-treated group based on some observable characteristics. As PSM satisfies the matching techniques, it provides the robust results show in table 5 . Some authors such as [39] used this approach to see the impact. The treatment is cyclone affected households and the non-treated or control is non-affected households. The result from PSM shows that those households that are affected by any of these two cyclones Sidr and Aila represent more degree of meal consumption vulnerability. As discussed in the result section, being affected by any of these cyclones, households increases the degree of vulnerability by 9 to 14 percentage point under three different matching methods. So it is clear from the result that cyclones really increase the meal consumption vulnerability. Vulnerability in meal consumption is not only address by cyclones, there are other factors such as seasonality in agriculture, infrastructure and political factors but cyclones plays an important role in making the households marginalized which is difficult to remove in short period of time.

\section{Conclusion}

From the discussion throughout the paper, it is evident that there is an impact of cyclones on vulnerability in the meal frequencies through the inherent form of marginalization. Climate change induced frequent cyclones are already apparent and will continue to appear in the near future. Bangladesh every year abruptly affected by this shock and loses lives and amenities to survive. The result shows that almost 9 to 14 percentage point increase in the meal consumption vulnerability due to cyclones' hit only. Besides, the seasonality in the agriculture induced by salinity in the cropping land put the households in to more vulnerable situation. Land degradation induced by the saline water hinders the traditional cropping system and impedes the production process and reduces the agricultural employment. The impact analysis of certain treatment such as cyclone victims arise the problem of selection biasness and make the result inconsistent. To resolve this problem, the paper used the propensity score matching technique which compares the disaster affected households with the non-affected households based on some observable characteristics. Various matching techniques established the causality of cyclones' effect on meal consumption vulnerability. Besides, some household and community characteristics established the marginality phenomenon of the households which drives them to extreme and moderate vulnerable positions. To uplift the marginalized poor households to a certain sustainable livelihood, some policy suggestions could be drawn from the above results. As it is nothing to do with the natural calamities such as cyclones, it is advisable to establish proper networking to provide safe-drinking water, sanitation and health services at the first point. Safe drinking water should be the first priority to fight vulnerability. The number of sick days could be reduced by implementing proper sanitation facilities to the households. Individual and as well as community level strives could solve the problem to some extent. The rural households should be encouraged to adopt saline intensified cropping varieties and mechanism to sustain their agricultural activities and for that market establishment is necessary. Households in this region should also diversify their income sources mostly in non-agricultural sectors and one possible way to deal with the seasonality in agriculture is to migrate to nearby cities where wage-employment is available for couple of months. So there is no one solution for the kind of multidimensional problem. Aid and assistance program can foster the process but it is the local households and the community that can play vital role to change their life.

\section{Acknowledgements}

The study is a part of a Master thesis chapter that was presented and submitted to the Faculty of Business Administration at Corvinus University of Budapest, Hungary \& Faculty of Agriculture, University of Bonn, Germany as in partial fulfilment of the requirements for the degree of Masters of Science. The author is grateful to Professor Dr. Imre Fertö, the first supervisor and Professor Dr. Thomas Heckelei, the second supervisor for their valuable directions. The study was supported by European Union's Erasmus Mundus Program through AFEPA consortium. The author is immensely indebted to Institute of Microfinance (InM) and Palli Karma-Sahayak Foundation (PKSF) for providing data for the study.

\section{References}

[1] UNDP, "A Global Report: Reducing disaster risk: A challenge for development," United Nations Development Programme, 2004.

[2] UNCCD, "United Nations Convention to Combat Desertification in Countries Experiencing Serious Drought and/or Desertification, Particularly in Africa," 1996. www.unccd.int/convention/text/convention.php 
[3] Nachtergaele, F., R. Biancalani, S. Bunning, and H. George, "Land Degradation Assessment: The LADA Approach", 19th World Congress of Soil Science, Brisbane, Australia, 2010.

[4] Nkonya, E., J. Pender, K. Kaizzi, E. Kato, S. Mugarura, H Ssali, and J. Muwonge, "Linkages between land management, land degradation, and poverty in Sub-Saharan Africa: The case of Uganda", IFPRI Research Report \#159, Washington D.C. $2008 \mathrm{a}$.

[5] Von Braun, Joachim and Gatzweiler, Franz W., Marginality: Addressing the Nexus of Poverty, Exclusion and Ecology, Springer. 2014.

[6] Blaikie, P., Cannon, T., Davis, I. and Wisner, B., At Risk: Natural Harards, People's Vulnerability, and Disasters. Routledge, London, UK. 1994.

[7] Ali, A., "Climate change impacts and adaptation assessment in Bangladesh," Climate Research, V. 12, 1999, pp.109-116.

[8] Paul, B. K., "Why relatively fewer people died? The case of Bangladesh's Cyclone Sidr," Natural Hazards, V. 50(2), 2009, pp. 289-304.

[9] GoB, Bangladesh climate change strategy and action plan. Government of the People's Republic of Bangladesh. 2009.

[10] Gray, W.M., “Tropical Cyclone Global Climatology,” WMO Technical Document WMO/TD No. 72, Vol. 1, WMO, Geneva, Switzerland, 1985, pp. 3-19.

[11] EMDAT, The International disaster database. Center for Research on the Epidemiology of Disaster. 2013. http://www.emdat.be/database.

[12] Paul, S. K. and Routray, J. K., "Household response to cyclone and induced surge in coastal Bangladesh: coping strategies and explanatory variables", Natural Hazards, V. 57(2), 2011, pp. 477-499.

[13] Nicholls, R.J.N., Mimura, N. and Topping, J.C., "Climate Change in South and South-east Asia: Some Implications for Coastal Areas", Journal of Global Environmental Engineering, V. 1, 1995, pp. 137-54.

[14] Knutson, T. R., McBride, J. L., Chan, J.; Emanuel, K., Holland, G., Landsea, C., Held, I., Kossin, J. P., Srivastava, A. K. \& Sugi, M., "Tropical cyclones and climate change," Nature Geoscience, vol 3, Nature Publishing Group, 2010. pp.157-163

[15] Mendelsohn, R.; Emanuel, K.; Chonabayashi, S. \& Bakkensen, L. The impact of climate change on global tropical cyclone damage Nature Climate Change, Nature Publishing Group, 2012, 2, pp. 205-209

[16] Schmuck, H., Living with the floods: Survival Strategies of Char-Dwellers in Bangladesh, Berlin: FDCL.1996.

[17] Rashid, S. F., "The Urban Poor in Dhaka City: Their Struggles and Coping Strategies during the Floods of 1998", Disasters, V. 24 (3), 2000, pp. 240-53.

[18] Del Ninno, C., Dorsch, P. A. and Smith, L. C., "Public policy markets and household coping strategies in Bangladesh: Avoiding a food security crisis following the 1998 floods," World Development, V.31 (7), 2003, pp. $1221-1238$.

[19] Rasid, H. and Haider, W., "Floodplain residents' preferences for water level management options in flood control projects in Bangladesh", Natural Hazards, V. 28(1), 2003, pp.
$101-129$.

[20] Brouwer, R., Akter, S., Brander, L. and Haque, E., "Socio-economic vulnerability and adaptation to environmental risk: A case study of climate change and flooding in Bangladesh," Risk Analysis, V. 27(2), 2007, pp. 313-326.

[21] Paul, S. K. and Routray, J. K., "Flood proneness and coping strategies: the experiences of two villages in Bangladesh", Disasters, V. 34(2), 2010, pp. 489-508.

[22] Dube, S. K., Sinha, P. C. and Roy, G. D., "Numerical Simulation of Storm Surges in Bangladesh Using A Bay-River Coupled Model", Coastal Engineering, V. 10(196), 1986, pp. 85-101.

[23] Madsen, H. and Jakobsen, F., "Cyclone induced storm surge and flood forecasting in the northern Bay of Bengal", Coastal Engineering, V. 51(4), 2004, pp. 277-296.

[24] Islam, T. and Peterson, R. E., "Tropical Cyclone Wind Characteristics for the Bangladesh Coast Using Monte Carlo Simulation", Journal of Applied Sciences, V. 8(9), 2008, pp. 1249-1255.

[25] Dube, S. K., Chittibabu, P., Sinha, P. C., Rao, A. D. and Murty, T. S., "Numerical Modelling of Storm Surge in the Head Bay of Bengal Using Location Specific Model", Natural Hazards, V. 31, 2004, pp. 437-453.

[26] Jakobsen, F. and Azam, M. H., "Cyclone Storm Surge Levels Along the Bangladeshi Coastline in 1876 and 1960-2000", Coastal Engineering Journal, V. 48(3), 2006, pp. 295-307.

[27] Islam, M. A., "Tropical cyclone, coastal Bangladesh" in G. F White (ed.), Natural Hazards: Local, National, Global, Oxford University Press, New York, 1974, pp. 19-24.

[28] Murty, T. S. and El-Sabh, M., "Mitigating the Effects of Storm Surges Generated by Tropical Cyclones- A Proposal", Natural Hazards, V. 6(3), 1992, pp. 251-273.

[29] Chowdhury, A. M. R., Bhuyia, A. U., Choudhury, A. Y. and Sen, R., "The Bangladesh cyclone of 1991: why so many people died," Natural Hazards, V. 17(4), 1993, pp. 291-304.

[30] Jalan, J., \& Ravallion, M., "Transient poverty in post-reform rural China", Journal of Comparative, Vol. 26, No. 2:1998, pp338-387.

[31] Chambers, R., "Editorial introduction: Vulnerability, coping and policy", IDS Bulletin 202: 7. 1989.

[32] Ligon E., and Schechter, L., "Evaluating different approaches to estimating vulnerability", Social protection discussion paper Series, No. 0410. 2004.

[33] Chaudhuri, S., Jalan, J., and Suryahadi, A., "Assessing household vulnerability to poverty from cross-sectional data: A methodology and estimates from Indonesia", Columbia University Economics Department Discussion Paper No.:010252, 2002.

[34] Armendariz, A., and Morduch, J., The economics of microfinance. Cambridge, Massachusetts: The MIT Press. 2005.

[35] Kochar, A., "Explaining household vulnerability to idiosyncratic income shocks", American Economic Review, 85(2), 1995, pp.159-1964. 
[36] Dercon, S., and Krishnan, P., "Vulnerability, seasonality and poverty in Ethiopia", Journal of Development Studies, Vol. 366 , No. 6, 2000, pp. 25-53.

[37] Günther, I., \& Harttgen, K., "Vulnerability to poverty in Madagascar", Background paper prepared for the World Bank Social Protection Unit. 2005.

[38] InM, "PRIME intervention in the coastal areas of south-west Bangladesh", Institute of Microfinance (InM), 2011.

[39] Khander, S.R., Khalily, B., and Samad, A., "Vulnerability to seasonal hunger and its mitigation in northwest Bangladesh", Working Paper No. 4, 2010, Institute of Microfinance (InM).

[40] Hasan, M Monirul, "Does credit improve the food consumption vulnerability of the extreme poor? - Empirical evidence from Bangladesh", MPRA Paper No. 28192. 2010 http://mpra.ub.uni-muenchen.de/28192/1/MPRA_paper_281 92.pdf

[41] InM, "Impact of PRIME interventions of Monga mitigation in greater Rangpur region in Bangladesh", Institute of
Microfinance $\quad 2010$. http://www.prosperprogram.org/cms/ItemlibManagement/Ite mLibrary/Doc/IL-208.pdf

[42] Khandker, S. R., Koolwal, G.B., and Samad, H. A., Handbook of impact evaluation- quantitative methods and practices. The World Bank. 2010.

[43] Godtland, E., Elisabeth, S., Alain, J., Rinku, M., and Oscar, O., "The impact of farmer- field-schools on knowledge and productivity: A study of potato farmers in the Peruvian Andes", Economic Development and Cultural Change, 52 (1), 2004, pp. 12958.

[44] Heckman, J., Ichimura, H., and Petra T., "Matching as an econometric evaluation estimator", Review of Economic Studies, 65 (2), 1998, pp. 261-94.

[45] Caliendo, M., and Kopeinig, S., "Some practical guidance for the implementation of propensity score matching", Journal of Economic Surveys, 22 (1), 2008, pp. 31-72.

[46] Sen, A., Poverty and Famines: An essay on entitlement and deprivation. Oxford University Press, New York, NY. 1981. 